\title{
Laparoscopic total gastrectomy and lymphadenectomy for remnant gastric cancer treatment
}

\author{
Adem Yüksel, ${ }^{1}$ Murat Coşkun, ${ }^{2}$ Fatih Sümer ${ }^{3}$ \\ 'Department of Gastrointestinal Surgery, Kocaeli Derince Training and Research Hospital, Kocaeli, Turkey \\ 2Department of General Surgery, Kocaeli Derince Training and Research Hospital, Kocaeli, Turkey \\ ${ }^{3}$ Department of Gastrointestinal Surgery, Inönü University Faculty of Medicine, Malatya, Turkey
}

\begin{abstract}
Surgery is the basis of treatment for remnant gastric cancer (RGC). The surgery consists of gastrectomy with meticulous lymphadenectomy. Gastrectomy and lymphadenectomy can be performed with minimally invasive surgical techniques. However, RGC surgery can be challenging in cases where changes occur following an earlier operation. The current report is a description of the surgical results of laparoscopic total gastrectomy and lymphadenectomy performed for a patient with a history of subtotal gastrectomy for gastric ulcer 19 years earlier who had cancer develop in the remnant stomach. The data regarding laparoscopic surgery for RGC is limited to case series. In the current study, a laparoscopic technique for RGC is presented in the context of a discussion of the key points of surgery.

Keywords: Gastrectomy; laparoscopic; remnant gastric cancer.
\end{abstract}

\section{Introduction}

Minimally invasive surgical techniques are widely used for the gastrointestinal system surgery. Currently, in early gastric cancer treatment, laparoscopic gastrectomy is accepted as a standard of care technique especially in Far Eastern countries. When compared to open surgery, laparoscopic gastrectomy has favorable pain, early recovery, and similar oncologic outcomes. ${ }^{[1]}$

Regardless of primary histopathology (benign or malign), remnant gastric cancer (RGC) develops from the residual gastric tissue of a patient who had a gastric resection history. The incidence of RGC is $1-8 \%$ of all gastric cancers. ${ }^{[2,3]}$

Laparoscopic surgery in the treatment of RGC is technically more challenging because of anatomic changes and tissue adhesions. Laparoscopy for treatment of RGC has not been accepted as a standard technique, yet.

In current study, we aimed to present a case of laparoscopic total gastrectomy and lymphadenectomy for remnant gastric cancer.

\section{Case Report}

A 72-year-old male patient with diagnosis of RGC was admitted to our outpatient clinic. In his past medical history, patient had an open gastrectomy with open surgical technique due to for peptic ulcer 19 years ago. He had a laparoscopic cholecystectomy history 4 years ago. A midline abdominal incision scar was present. No abnormality was detected in the laboratory examination. In the 
endoscopy for gastrointestinal reconstruction a Billroth II gastrojejunostomy form was noticed. An ulcerovegetan mass was detected on the gastrojejunostomy line with endoscopy. Endoscopic biopsy histopathology was reported for as adenocarcinoma. There were multiple liver cystics were detected with computed tomography scan. A wall thickening with intense Fluoro 2 Deoxy D Glucose (FDG) uptake in the anastomosis line was detected with Positron Emission computed Tomography (PET-CT) scan. No pathological involvement was recorded elsewhere.

\section{Surgical Technique}

The patient was given the reverse trendelenburg position with both legs open. The first laparoscopic port was inserted $4 \mathrm{~cm}$ left lateral side of the umbilicus by open surgical technique. Adhesions were released by placing $5 \mathrm{~mm}$ port $3 \mathrm{~cm}$ below the the arcus costarum and left anterior axillary line intersection. Subsequent ports placement shown in Figure 1. No liver traction was needed due to diaphragma and left liver lobe adhesions. Harmonic Scalpel (Harmonic Scalpel, Ethicon EndoSurgery Inc., Cincinnati, $\mathrm{OH}, \mathrm{USA}$ ) and Ligasure (Valleylab, Boulder, CO, USA) were used for adhesiolysis and dissection. Billroth II anastomosis was antecolic. Omentum was released from transverse colon and lifted cranially. Posterior stomach was accessed through omental bursa with omentectomy. Afferent and efferent ans were transected $5 \mathrm{~cm}$ distal to the gastrojejunostomy anastomosis. Surgical resection widened to

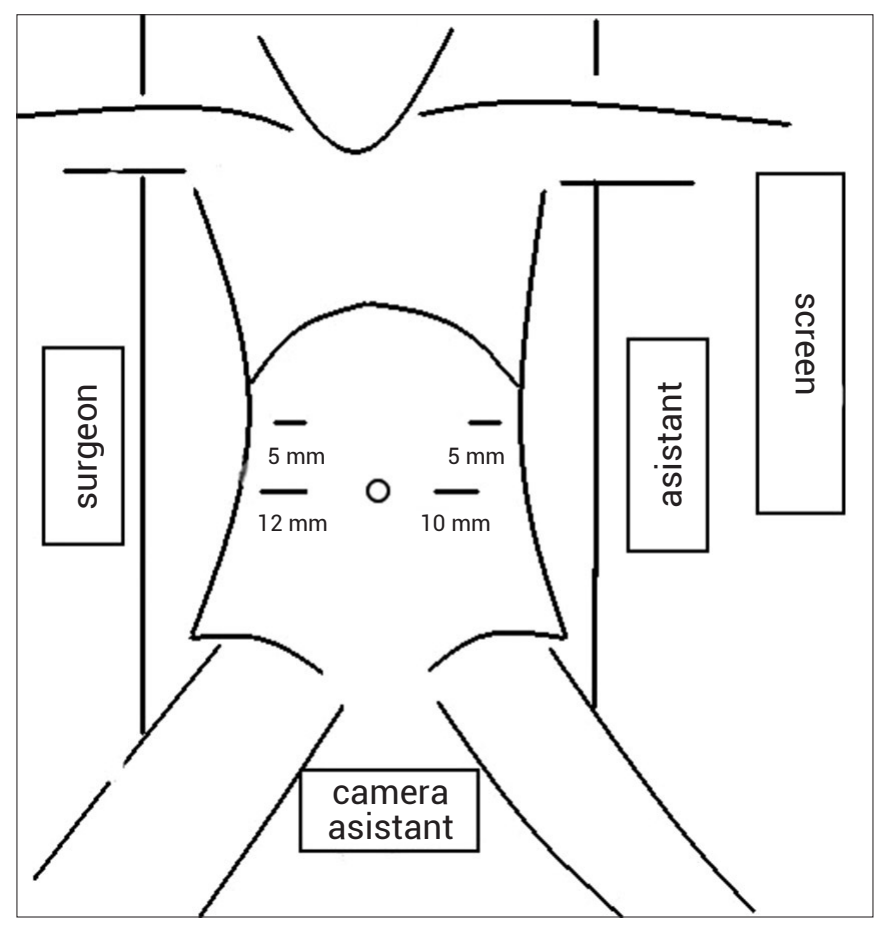

Figure 1. Patient position and port placement. include mesenterium of small intestine. The stomach was released and lymph node dissection was performed according to Japanese Gastric Cancer Treatment Guide. ${ }^{[4]}$ (Fig. 2). A $2 \mathrm{~cm}$ gastrotomy extending from esophagogastric junction to esophagus was performed. Right $12 \mathrm{~mm}$ port was dilated and $25 \mathrm{~mm}$ anvil introduced to abdominal cavity. The anvil was advanced from the gastrotomy line toward the esophagus (Fig. 3). A 2/0 prolene tied to the tip of the anvil. Anvil placed in esophagus, prolene was extracted from the anterior esophageal wall (Fig. 4). Gastrectomy was done by transecting the esophagus nearly beneath the area where the endoscopic stapler and anterior suture exits (Fig. 5). Anastomosis of the distal side esophagojejunostomy was completed with a $25 \mathrm{~mm}$ circu-

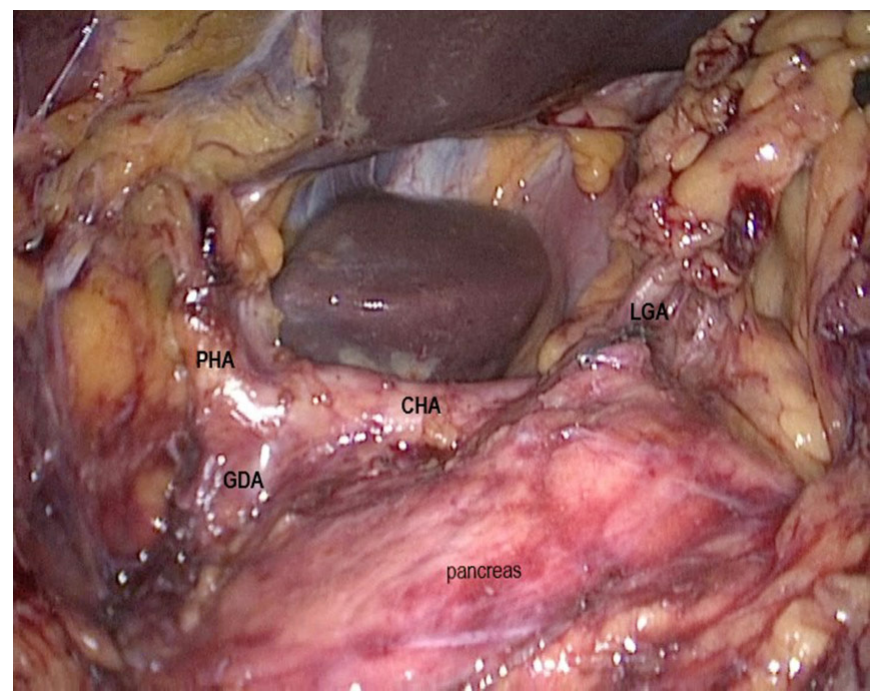

Figure 2. Lenf Node Dissection (GDA: Gastroduodenal artery, PHA: Proper Hepatic Artery, CHA: Common Hepatic Artery, LGA: Left Gastric Artery), LGA: Left Gastric Artery).

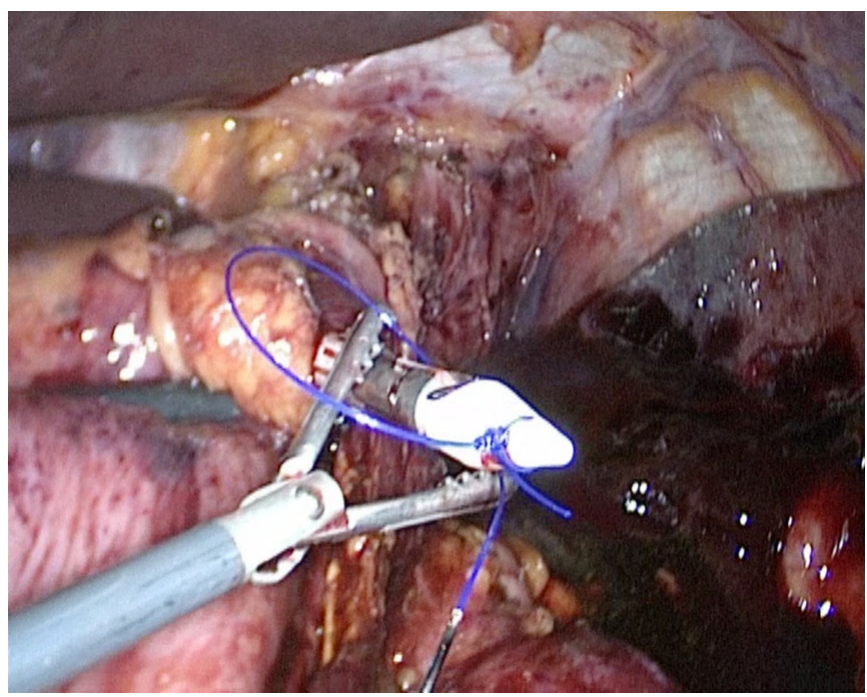

Figure 3. Placement of the anvil in the esophagus. 


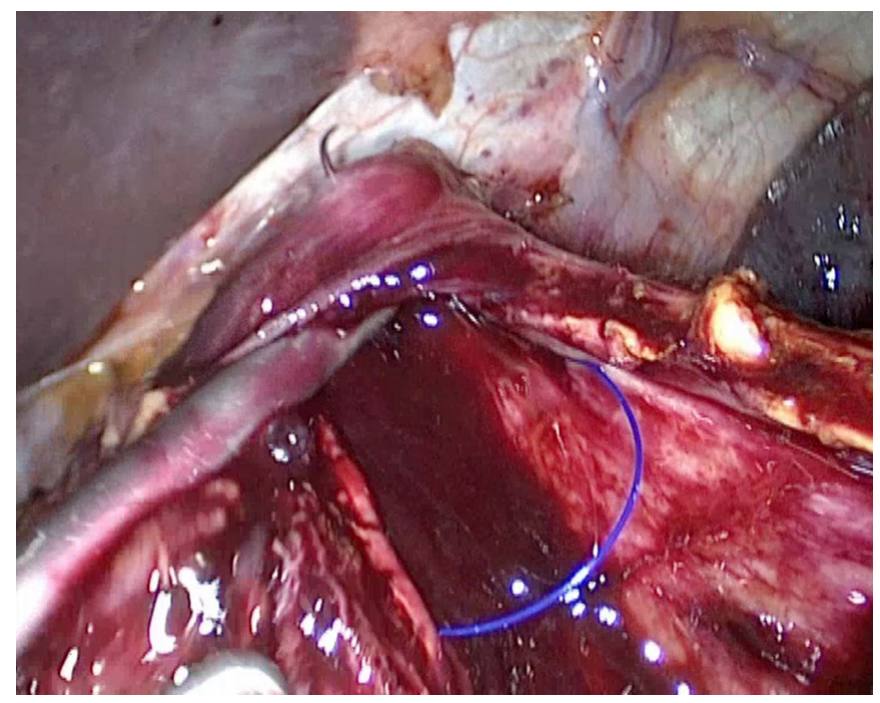

Figure 4. Suture sticking out from the anterior wall of the esophagus.

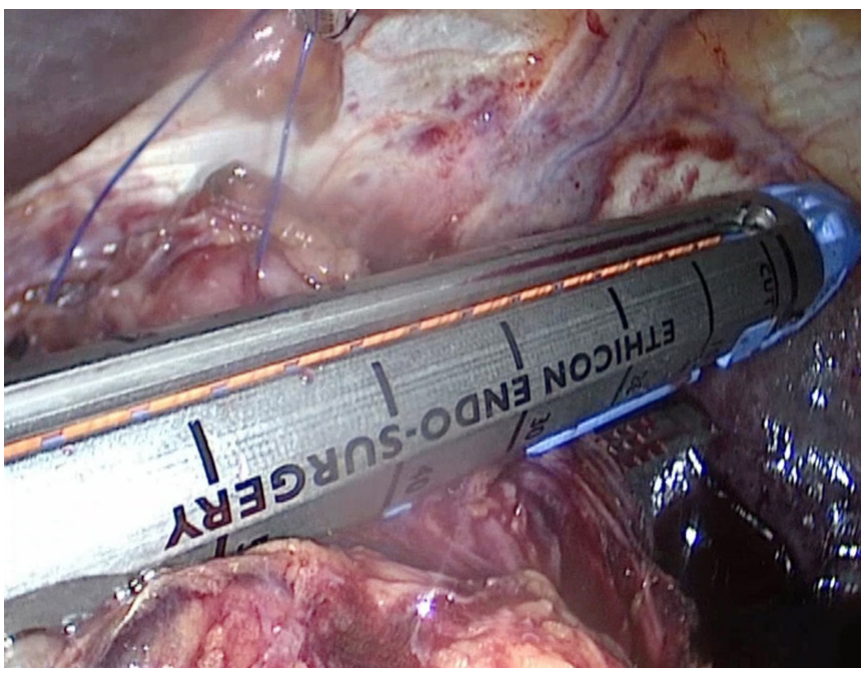

Figure 5. Transection of the esophagus with stapler.

lar stapler from the dilated right $12 \mathrm{~mm}$ port. Afferent ans was short and angular which did not allow a proper intracorpearal anostomosis. The left $12 \mathrm{~mm}$ port expanded, wound protector ecarteur was placed and pathological specimen was extracted. Anastomosis of jejunojejunostomy was done $40 \mathrm{~cm}$ distal to the esophagojejunostomy line. The duration of operation was 345 minutes. A total of $150 \mathrm{ml}$ intraoperative bleeding was recorded.

The oral intake was allowed at postoperative $5^{\text {th }}$ day. The patient was discharged at postoperative $7^{\text {th }}$ day (Fig. 6). Histopathological result was low differentiated adeno-carcinoma, tumor invaded subserosa and 4 of 25 lymph nodes were involved with carcinoma metastasis. The nearest surgical margin of the tumor was $5.4 \mathrm{~cm}$. Patient was staged as 3A (T3N2MO) according to the TNM staging system (American Joint Committee on Cancer (AJCC), $7^{\text {th }}$ edition).

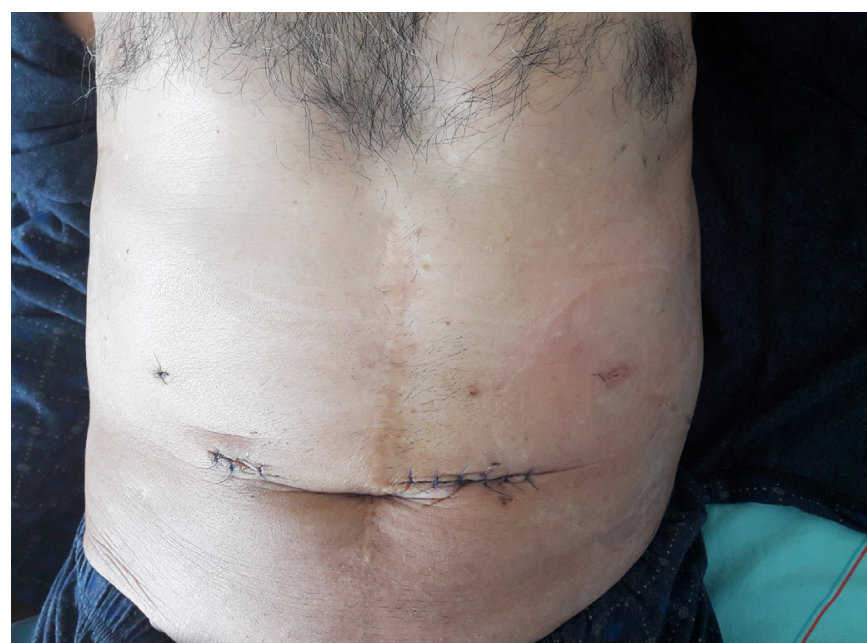

Figure 6 . Wounds of port sites.

\section{Discussion}

Laparoscopic gastrectomy is considered as standard approach in early gastric cancer especially in the Far Eastern countries because of the reduction of postoperative morbidity and shortening hospitalization, as well as oncologic outcomes similar to open surgery. ${ }^{[5]}$ Today, technological advances in high-resolution video systems, staplers, energy devices and vascular sealing devices have provided opportunity to the expansion of indications for laparoscopic surgery and more complex cases to be made with this technique.

In the treatment of remnant gastric cancer, gastrectomy is the basis of treatment with radical lymphadenectomy as well as primary gastric cancer. ${ }^{[4]}$ The first laparoscopy experience in remnant gastric cancer surgery was reported in $2005 .{ }^{[6]}$ From this date to present, case series with laparoscopy assisted or total laparoscopic resections and limited number of patients have been reported in literature, especially from far eastern countries. ${ }^{[7-9]}$ Previous abdominal surgery causes some technical difficulties in laparoscopic surgery. Pneumoperitoneum formation, port insertion and to ensure adequate visibility safely are the most basic difficulties. Neverthless, studies have reported that after previous abdomen surgery, laparoscopic gastric and colorectal surgery can be performed with a higher risk of conversion to open surgery. ${ }^{[10,11]} \mathrm{A}$ small number of studies on gastric cancer reported open conversion rate as $0-47.1 \%{ }^{[7]}$ The most important reason of conversion to open surgery is existence of serious complications in the abdomen, and these adhesions are more serious in patients who have previously undergone gastrectomy due to malignancy. For this reason, it has been reported 
that patients operated for benign reasons might be more appropriate to perform gastrectomy for laparoscopic surgery, whereas operated patients with malign reasons have serious intraabdominal adhesions and this might increase conversion rates at the operation. ${ }^{[7,12]}$ In addition to these difficulties, the technical difficulty we encountered was the shortness of the afferent ans in patients who had previously undergone Billroth II reconstruction. Manipulation of jejunojejunostomy anastomosis ans is difficult at reconstruction stage after partially wide resection of afferent ans with mesentery due to tumor surgery. This problem can be solved by releasing the Treitz ligament. Because of the need for an additional trochar for anastomosis, this anastomosis was done with open technique from the area where the specimen was removed in our case.

LTG is also an important step in the reconstruction operation. Many different techniques have been described in the literature, especially regarding esophagojejunostomy. ${ }^{[13]}$ In our case, we modified the technic described by Omori et al. ${ }^{[14]}$ and anastomosis of the esophagojejunostomy was performed. Differently from the technique originally described, the incision of the skin and fascia was expanded to the extent that the circular staplers and the anvil could pass through, and anastomosis was completed.

In laparoscopic RGC surgeries, another point is the suffeciency of oncologic outcomes. Removal of 1-11 lymph node stations with lymph node dissection and resection of the $10 \mathrm{~cm}$ jejunum mesentery in the presence of Billroth II reconstruction is recommended. ${ }^{[4]}$ The number of lymph nodes removed is an important indicator to evaluate the sufficiency of the oncologic surgeon. An average of 22 lymph nodes were removed with laparoscopic surgery and this result was reported to be similar to the open surgical technique. ${ }^{[8]}$

In conclusion, despite some technical difficulties, laparoscopic gastrectomy in the treatment of RGC is feasible technique when safe pneumoperitoneum was formed and advanced laparoscopic techniques such as appropriate adhesiolysis and anastomosis techniques can be performed.

\section{Disclosures}

Informed Consent: Written informed consent was obtained from the patient for the publication of the case report and the accompanying images.

Peer-review: Externally peer-reviewed.
Conflict of Interest: None declared.

\section{References}

1. Xiong JJ, Nunes QM, Huang W, Tan CL, Ke NW, Xie SM, et al. Laparoscopic vs open total gastrectomy for gastric cancer: a meta-analysis. World J Gastroenterol 2013;19:8114-32.

2. Sinning C, Schaefer N, Standop J, Hirner A, Wolff M. Gastric stump carcinoma - epidemiology and current concepts in pathogenesis and treatment. Eur J Surg Oncol 2007;33:1339. [CrossRef]

3. Mezhir JJ, Gonen M, Ammori JB, Strong VE, Brennan MF, Coit DG. Treatment and outcome of patients with gastric remnant cancer after resection for peptic ulcer disease. Ann Surg Oncol 2011;18:670-6. [CrossRef]

4. Japanese Gastric Cancer Association. Japanese gastric cancer treatment guidelines 2014 (ver. 4). Gastric Cancer 2017;20:1-19. [CrossRef]

5. Li Z, Wang Q, Li B, Bai B, Zhao Q. Influence of enhanced recovery after surgery programs on laparoscopy-assisted gastrectomy for gastric cancer: a systematic review and metaanalysis of randomized control trials. World J Surg Oncol 2017;15:207. [CrossRef]

6. Yamada H, Kojima K, Yamashita T, Kawano T, Sugihara K, Nihei Z. Laparoscopy-assisted resection of gastric remnant cancer. Surg Laparosc Endosc Percutan Tech 2005;15:226-9.

7. Son SY, Lee CM, Jung DH, Lee JH, Ahn SH, Park DJ, et al. Laparoscopic completion total gastrectomy for remnant gastric cancer: a single-institution experience. Gastric Cancer 2015;18:177-82. [CrossRef]

8. Tsunoda S, Okabe H, Tanaka E, Hisamori S, Harigai M, Murakami $\mathrm{K}$, et al. Laparoscopic gastrectomy for remnant gastric cancer: a comprehensive review and case series. Gastric Cancer 2016;19:287-92. [CrossRef]

9. Nagai E, Nakata K, Ohuchida K, Miyasaka Y, Shimizu S, Tanaka M. Laparoscopic total gastrectomy for remnant gastric cancer: feasibility study. Surg Endosc 2014;28:289-96.

10. Barleben A, Gandhi D, Nguyen XM, Che F, Nguyen NT, Mills $S$, et al. Is laparoscopic colon surgery appropriate in patients who have had previous abdominal surgery? Am Surg 2009;75:1015-9.

11. Tokunaga M, Hiki N, Fukunaga T, Nunobe S, Ohyama S, Yamaguchi T. Laparoscopy-assisted gastrectomy for patients with earlier upper abdominal open surgery. Surg Laparosc Endosc Percutan Tech 2010;20:16-9. [CrossRef]

12. Liao G, Wen S, Xie X, Wu Q. Laparoscopic gastrectomy for remnant gastric cancer: Risk factors associated with conversion and a systematic analysis of literature. Int J Surg 2016;34:17-22. [CrossRef]

13. Wei G, Zheng J, Li Y. Reconstruction after LATG: technical tips and pitfalls. Transl Gastroenterol Hepatol 2017;2:41.

14. Omori T, Oyama T, Mizutani S, Tori M, Nakajima K, Akamatsu $\mathrm{H}$, et al. A simple and safe technique for esophagojejunostomy using the hemidouble stapling technique in laparoscopy-assisted total gastrectomy. Am J Surg 2009;197:e13-7. [CrossRef] 